\title{
The impact of physician denial upon patient autonomy and well-being
}

\author{
Christopher Meyers Bakersfield, USA
}

\section{Author's abstract}

It is now widely accepted that a patient's ability to engage in autonomous decision-making can be seriously threatened when she denies significant aspects of her medical condition. In this paper I use a true case to reveal the harmful effects of physician denial upon patient autonomy and well-being. I suggest further that such physician denial may be more common than is generally acknowledged, since aspects of the contemporary medical ethos likely serve to reinforce rather than to undercut such denial.

It is now widely accepted that patients sometimes deny particularly troubling aspects of their illness (1). A powerful case can also be made that even in its 'normal' form (2), such denial can detrimentally affect patients' ability to engage in autonomous decision-making (3).

Little attention has been paid, however, to the effect of physician denial on patients' ability to choose rational, ethically sound medical or life goals (4). The following true case describes a situation in which a physician's denial had a negative impact not only upon the autonomy of his patient's family, but also upon both the patient's and his family's well-being. While this physician's response may not represent the norm in patient care, I argue that whenever denial of this sort is present it represents a threat to autonomy and wellbeing. Further, I suggest in conclusion that elements present in the contemporary medical ethos may serve to reinforce rather than to undercut such denial.

\section{The case}

JT, a three-month-old infant boy born to a mother unknowingly infected with herpes, had been hospitalised since birth in a neonatal intensive care unit. The herpes had attacked the child's liver, rendering it non-functional. Because of the near certainty that the herpes would recur and attack any new organ, JT had been deemed an unacceptable candidate for transplant.

By this point JT had become severely jaundiced with dark yellow colouring. This unattractive appearance,

\section{Key words}

Physician denial; patient autonomy; patient well-being. coupled with a fatal prognosis, resulted in general avoidance by both nursing and medical staff. Further, his emotional isolation was compounded by the fact that his mother was undergoing considerable emotional trauma as she attempted to divorce her husband, the source of the herpes. In short, JT was rarely held and almost never visited.

The nursery was led by a department head who strongly advocated a sanctity-of-life position and the nursery's medical philosophy was one of employing all means to preserve life. Various members of the medical team repeatedly voiced a 'never say die' attitude. They fought long and hard to save even the earliest premature babies, rarely acknowledging the long-term hardships sometimes associated with such efforts. Despite this aggressive approach, however, the team consistently acknowledged on rounds and in formal case conferences that JT's condition was irreversibly fatal. They would speak at length about the technical aspects of his illness, citing the manner in which the herpes had destroyed the liver's vital ability to excrete bile and to metabolise necessary vitamins.

Outside the formal environment of the ward, though, the attending physician's attitude changed significantly. Over coffee one morning I asked why the team kept JT in the nursery (one of the most expensive medical wards in the state) rather than sending him home to die. He was genuinely surprised by the question. He seemed sincerely to believe they would be able to save JT's life. In confusion, I repeated the details expressed only hours earlier on rounds, including the medical fact that JT's liver, an organ vital to life, would never function adequately. He again acknowledged all these medical details but refused to draw the corresponding conclusion that he could not prevent JT from dying. Instead, he insisted, JT would be kept in the nursery and given all available treatment.

\section{Analysis of the case}

It seems clear that JT's physician was engaged in what Leo Goldberger describes as normal denial (2). His general grasp of reality was altogether rational and coherent, anything but 'psychotic'. He was a talented and dedicated doctor, interesting to work with and to engage in conversations about current affairs. Yet 
despite his otherwise cogent connection with the world, he could not accept the fact of JT's condition.

Given the 'never say die' philosophy of the nursery, given the explicitly stated belief that all costs should be expended in the effort to preserve life, JT's illness simply did not fit. No matter how much effort and cost was extended, this otherwise healthy child would die from liver failure. Hence JT's case represented precisely that which Goldberger explains is the source of most cases of normal denial - a specific conflictual or painful situation resulting in a refusal to accept reality.

The physician readily acknowledged the medical facts, yet he was unable to accept what these facts meant - that JT would die regardless of the team's efforts. Denial allowed him to be both a rational scientist concerned only with objective facts and a dedicated physician who never gave up on a patient. That is, the denial allowed him genuinely to believe contradictory notions: although JT's medical prognosis was terminal, he was not going to die (5).

\section{The ramifications of physician denial}

Physician denial sometimes produces clearly positive results, in particular by creating a relentless effort to overcome the inevitable, occasionally thereby helping to bring about unexpected improvements. As Norman Cousins puts it:

'In a sense, the physician who treats a terminally ill patient is himself practising a form of denial. He battles malignancy against heavy odds, employing his special knowledge and a wide array of methods and techniques ... . It is natural that both physician and patient should refuse to go down without a fight, and defeat is deferred or deflected often enough to give a quality of realism to the encounter' (6).

Physician denial, however, may also cause direct harm to patient autonomy and well-being. In JT's case, it imposed harm upon the infant and his mother while also restricting the mother's autonomy.

First, denial of the inevitable resulted in JT's slow and lonely death being needlessly prolonged. Various infections occurred during the course of his hospital stay, which, if left untreated, would have brought about a quicker and less painful death. Similarly, although sending JT home would have resulted in an earlier demise, at least he would have died while in the loving care of his family.

If JT's continued life had had some significant goods attached to it, a better case could have been made for continuing treatment. But given the low quality of life he did and would enjoy, such goods simply were not present, at least not to a degree sufficient to justify the associated harms suffered both by him and his mother (7). Hence, by insisting that treatment was of eventual value, JT's physician was no longer protecting life but merely prolonging death.

Second, although she rarely visited the ward, the mother was in regular contact with the physician and thus involved, at least to a minimal extent, in treatment decisions. As a result of her not being a direct participant, the mother was even more reliant upon the physician for accurate information, information needed to make rationally informed decisions for JT. And since the physician consistently reassured her that treatment was of medical value, she naturally agreed to its continuation. Receiving information made false because of the physician's denial, the mother continued to retain hope in a clearly hopeless situation. This false information prevented her from making an accurate assessment of her situation and thus prevented her from making an autonomous decision about her life and that of her child. In short, the physician's denial undercut the mother's autonomy.

Further, in addition to having her autonomy violated, the mother suffered a variety of other harms. Because she had been made to believe another outcome was likely, she was not prepared for JT's eventual death, especially as it came within the context of the 'death' of her marriage. She also suffered economically; given the extended length of JT's hospital stay, the bills proved devastating. Even with a decent insurance plan, the family's savings were depleted long before all the hospital bills were covered. The department head was not unaware of these costs, but refused, in his terms, 'to weigh lives against money. This is a very rich culture. We can easily pay for all of our medical needs. We simply have to get ous priorities straight'. While he may indeed hold an accurate assessment of the distribution of resources in the United States, this was of little consolation to JT's mother. Her financial life was being destroyed and with it many of her options for the future. And while economic harms alone will rarely if ever morally justify discontinuing treatment, they are almost always relevant to determinations of the most appropriate treatment option. In this case, those financial harms simply add to an otherwise compelling argument for terminating treatment.

\section{Denial and the professional ethos}

It is very important to note that these harms - to JT and to the mother's autonomy, psychological health, and financial status - were not the result of malicious intent. JT's physician truly believed that he could prevent JT from dying, that his and the team's efforts would be to JT's benefit. Unfortunately these beliefs were clouded by denial-created confusion.

It is also important to realise that this type of physician denial, in order to be sustained, must be socially reinforced. As Goldberger notes, normal denial is an integral component of social and professional groups; it allows such groups to retain a mutually defined sense of 'reality' (8). In JT's case, the physician's denial clearly was not 'psychotic'. On the contrary, it was consistent with the medical profession's self-image of being the protectors of the sanctity of life. The physician's job, this ethos maintains, is to save life, not to hasten death. 
Roger Crisp nicely captures the effect of the medical ethos in his discussion about whether physicians and nurses should be called upon to bring about death in euthanasia cases:

'Those involved with treating the sick often speak of medicine as a kind of "religion", to which they have dedicated their lives ... . They develop, and hence feel a strong desire to act upon, dispositions to save lives, not to end them. It is these dispositions, indeed, which lie at the base of much criticism of modern medical care, in cases such as those of Karen Ann Quinlan or Donald C [patients who were kept alive against their or their families' wishes]' (9).

Egilde Servalli reaches a similar conclusion: 'Physicians may not be able to handle the situation [of a dying patient] either as physicians or as bystanders. Perhaps, as a result of their education and conditioning, physicians are afraid to feel helpless and to project hopelessness to their patients ... . Most feel that it is their responsibility to keep patients alive, almost unconditionally' (10). And as Charles Bosk has shown, these dispositions, attitudes, and fears are first cultivated in medical school, reinforced and strengthened in residency, and then professionally maintained through such institutional structures as morbidity and mortality conferences (11).

Thus, that JT's physician believed he could save JT did not strike other members of the health care team as odd or irrational; if anything it was part of his and their professional duty. He was able to maintain his normal denial, even though such maintenance required simultaneously believing contradictory ideas, because it was reinforced by the dominant beliefs, the 'dispositions', of both his immediate social group and his profession.

The amount of harm brought about by the physician in this case is unusual because the circumstances surrounding JT and his mother are so extreme. The case does illustrate, however, the potential for harm associated with physician denial, both in terms of direct suffering and in terms of violating patient autonomy. Indeed, the questions posed by JT's case are whether it represents an aberration or whether the kind of denial expressed by his physician may be a routine response, given the socially reinforced beliefs integral to the profession's self-conception. If the latter is true, while the degree of harm suffered by JT and his family may be rare, the kind of harm may be much more common than readily acknowledged.

Christopher Meyers, PhD, is Associate Professor of Philosophy and Executive Director of the Kegley Institute of Ethics, Califormia State University, Bakersfield, California, USA.

\section{References and notes}

(1) See, for example, Edelstein E L, Nathanson D L, Stone A M, eds. Denial: a clarification of concepts and research. New York: Plenum Press, 1989; Breznitz S, ed. The denial of stress. New York: International Universities Press, 1983; Shelp E E, et al. Denial in clinical medicine: a re-examination of the concept and its significance. Archives of internal medicine. 1985; 145: 697-699; and Douglas C J, et al. Denial of illness: a reappraisal. General hospital psychiatry 1987; 9: 53-57.

(2) Leo Goldberger describes 'normal' denial as a common defensive response directed aginst 'a fairly specific conflictual or painful situation .... . [It is] a refusal to recognise the reality of a traumatic perception'. By contrast, 'psychotic' denial is a rejection of 'a large area of external reality' and thus creates a range of psychological trauma. Goldberger L. The concept and mechanisms of denial. See reference (1): Breznitz S: 8587.

(3) See, for example, Ackerman T. Why doctors should intervene. Hastings Center report 1982; 12: 14-17; Hardison, J. Uninformed consent and terms without definitions [editorial]. The American journal of medicine 1983; 74: 932-933; Kubler-Ross E. On death and dying. New York: Macmillan, 1969: 38-50; and Roth L, et al. The dilemma of denial in the assessment of competency to refuse treatment. American journal of psychiatry 1982; 139: 910-913.

(4) My search turned up only two references to physician denial: Hardison J. On denial [editorial]. The Americanjournal of medicine 1980; 69: 332-333; and Cousins N. Denial: are sharper definitions needed? Fournal of the American Medical Association 1982; 248: 210-212. Both articles focus only briefly on the concept, however, and neither discusses the impact of physician denial upon patient autonomy or well-being.

(5) How one can simultaneously maintain contradictory beliefs has been of longstanding philosophical concern, captured particularly in the literature on self-deception. I will not attempt to add to that extensive literature in this paper, other than to note that this and similar examples suggest the problem is not whether selfdeception of this sort is possible, but how it can be explained in a coherent philosophy of mind. For an excellent summary and bibliography of work in this area see Mele J. Recent work on self-deception. American philosophical quarterly 1987; 24: 1-17.

(6) See reference (4): 212 .

(7) For one of the many discussions of how health care practitioners may approach making this kind of determination see Meyers C. Intended goals and appropriate treatment: an alternative to the ordinary/ extraordinary distinction. Foumal of medical ethics 1984; 10: $128-130$.

(8) See reference (2): 87.

(9) Crisp R. A good death: who best to bring it? Bioethics $1987 ; 1: 75$.

(10) Servalli E P. The dying patient, the physician, and the fear of death. New England journal of medicine 1988; 319: 1729. See also the subsequent discussion in $1989 ; 320$ : 1557-1558.

(11) Bosk C L. Forgive and remember: managing medical failure. Chicago: University of Chicago Press, 1979. 